\title{
Storage Coefficients and Permeability Functions for Coal-Bed Methane Production Under Uniaxial Strain Conditions
}

\author{
Simon A. Mathias ${ }^{1} \cdot$ Stefan Nielsen ${ }^{1} \cdot$ Rebecca L. Ward ${ }^{1}$
}

Received: 30 April 2019 / Accepted: 10 August 2019 / Published online: 20 August 2019

(C) The Author(s) 2019

\begin{abstract}
The porosity and permeability of coal change with pore pressure, due to changes in effective stress and matrix swelling due to gas adsorption. Three analytical models to describe porosity and permeability change in this context have been presented in the literature, all of which are based on poroelastic theory and uniaxial strain conditions. However, each of the three models provides different results. Review articles have attributed these differences to the use of stress formulations or strain formulations. In this article, the three aforementioned porosity models are used to derive three associated expressions for the storage coefficient. A single mathematical equation for the storage coefficient in an aquifer under uniaxial strain conditions is well established. The storage coefficient represents the volume of fluid released per unit volume of a porous rock following a unit decline in pore pressure. It is shown that only one of the aforementioned three coal-bed methane porosity models leads to the correct equation for the uniaxial strain storage coefficient in the absence of gas sorption-induced strain.
\end{abstract}

Keywords Coal-bed methane $\cdot$ Permeability $\cdot$ Porosity $\cdot$ Storage coefficient $\cdot$ Matrix shrinkage $\cdot$ Rock mechanics

\section{List of Symbols}

$C_{\mathrm{g}}$ Compressibility of the gaseous methane $\left(\mathrm{M}^{-1} \mathrm{LT}^{2}\right)$

$C_{\mathrm{p}}$ Seidle's compressibility parameter $\left(\mathrm{M}^{-1} \mathrm{LT}^{2}\right)$

$E$ Young's modulus $\left(\mathrm{ML}^{-1} \mathrm{~T}^{-2}\right)$

$f \quad$ Palmer and Mansoori's model parameter (-)

$g$ Gravitational acceleration $\left(\mathrm{LT}^{-2}\right)$

$G \quad$ Shear modulus $\left(\mathrm{ML}^{-1} \mathrm{~T}^{-2}\right)$

k Permeability tensor $\left(\mathrm{L}^{2}\right)$

\author{
Simon A. Mathias \\ s.a.mathias@durham.ac.uk \\ Stefan Nielsen \\ stefan.nielsen@durham.ac.uk \\ Rebecca L. Ward \\ rebecca.1.ward@durham.ac.uk \\ 1 Department of Earth Sciences, Durham University, Durham, UK
}


$k \quad$ Isotropic permeability $\left(\mathrm{L}^{2}\right)$

$K$ Bulk modulus $\left(\mathrm{ML}^{-1} \mathrm{~T}^{-2}\right)$

$k_{0} \quad$ Reference permeability $\left(\mathrm{L}^{2}\right)$

$M_{\mathrm{g}}$ Mass of gaseous methane (M)

$m_{\mathrm{g}}$ Mass of gaseous methane per unit bulk volume of coal $\left(\mathrm{ML}^{-3}\right)$

$M_{S}$ Mass of adsorbed methane (M)

$P_{\mathrm{p} 0}$ Reference pore pressure $\left(\mathrm{ML}^{-1} \mathrm{~T}^{-2}\right)$

$P_{\mathrm{L}} \quad$ Langmuir isotherm pressure $\left(\mathrm{ML}^{-1} \mathrm{~T}^{-2}\right)$

$P_{\mathrm{m}}$ Partial pressure of the adsorbed methane $\left(\mathrm{ML}^{-1} \mathrm{~T}^{-2}\right)$

$P_{\mathrm{p}}$ Pore pressure $\left(\mathrm{ML}^{-1} \mathrm{~T}^{-2}\right)$

$S \quad$ Storage coefficient $\left(\mathrm{M}^{-1} \mathrm{LT}^{2}\right)$

$T$ Temperature $(\Theta)$

$t$ Time (T)

$V_{\mathrm{b}}$ Bulk volume $\left(\mathrm{L}^{3}\right)$

$V_{\mathrm{m}}$ Volume of coal mineral $\left(\mathrm{L}^{3}\right)$

$V_{\mathrm{p}}$ Pore volume $\left(\mathrm{L}^{3}\right)$

$z \quad$ Elevation (L)

$\alpha \quad$ Biot coefficient (-)

$\varepsilon \quad$ Strain tensor $(-)$

$\varepsilon_{\mathrm{b}} \quad$ Bulk volume strain (-)

$\varepsilon_{\mathrm{L}} \quad$ Langmuir isotherm strain (-)

$\varepsilon_{\mathrm{m}} \quad$ Mineral volume strain (-)

$\varepsilon_{\mathrm{S}} \quad$ Shrinkage strain associated with methane adsorption (-)

$\eta \quad$ Permeability exponent (-)

$\lambda \quad$ Lamé parameter $\left(\mathrm{ML}^{-1} \mathrm{~T}^{-2}\right)$

$\mu_{\mathrm{g}}$ Dynamic viscosity of gaseous methane $\left(\mathrm{ML}^{-1} \mathrm{~T}^{-1}\right)$

$v$ Poisson's ratio (-)

$\rho_{\mathrm{g}} \quad$ Density of gaseous methane $\left(\mathrm{ML}^{-3}\right)$

$\rho_{\mathrm{S}} \quad$ Density of the adsorbed methane $\left(\mathrm{ML}^{-3}\right)$

$\boldsymbol{\tau}$ Stress tensor $\left(\mathrm{ML}^{-1} \mathrm{~T}^{-2}\right)$

$\tau_{\mathrm{h}} \quad$ Hydrostatic stress $\left(\mathrm{ML}^{-1} \mathrm{~T}^{-2}\right)$

$\tau_{\mathrm{m}}$ Mean stress $\left(\mathrm{ML}^{-1} \mathrm{~T}^{-2}\right)$

$\phi \quad$ Porosity (-)

$\phi_{0} \quad$ Reference porosity (-)

\section{Introduction}

There are several previously published derivations of analytical models to describe how the porosity and permeability of coal change due to changes in pore pressure. Knowledge about how porosity and permeability evolve is important to help estimate the productivity of coal-bed methane production wells (Liu and Harpalani 2013) in addition to forecasting potential hydromechanical impacts on surrounding geological formations during coal-bed methane production (Wu et al. 2018). Permeability of coal is mostly attributed to the cleats within a given coal formation. As pore pressure is reduced, the effective stress is increased, which leads to a reduction in coal cleat apertures and hence a reduction in coal porosity and permeability. However, reductions in pore pressure also lead to desorption of gas from the coal matrix, which in turn leads to shrinkage of the coal matrix, an increase in coal cleat apertures, and an increase in coal cleat permeability. Of interest in the present work are the 
differences between the associated analytical models of Palmer and Mansoori (1998), Shi and Durucan (2004), and Cui and Bustin (2005). These three models all claim to satisfy uniaxial strain conditions, with gas sorption-induced strain (GSIS) treated as analogous to thermal expansion. The fact that the three models provide different results has been attributed to Palmer and Mansoori (1998) adopting a strain formulation, whereas Shi and Durucan (2004) and Cui and Bustin (2005) adopted a stress formulation (Gu and Chalaturnyk 2006; Palmer 2009; Liu and Harpalani 2013; Li et al. 2017). This explanation is unsatisfactory, firstly because it does not explicitly explain the difference between the models of Shi and Durucan (2004) and Cui and Bustin (2005), and secondly, because, if the same theoretical assumptions have been made, the final results should be the same regardless of whether a stress-based or strain-based formulation is used.

Analytical solutions for porosity change due to pore pressure under uniaxial strain conditions have also been derived in the context of fluid production/injection in aquifers (e.g., Gambolati et al. 2000; Jaeger et al. 2007; Zimmerman 2017; Andersen et al. 2017). Associated authors presented a single common equation for the storage coefficient, which they rigorously derived from poroelastic theory. The storage coefficient represents the volume of fluid released per unit volume of a porous rock following a unit decline in pore pressure. In this article, we derive equations for this aforementioned storage coefficient using the three different porosity models of Cui and Bustin (2005), Palmer and Mansoori (1998), and Shi and Durucan (2004). We look at the limits of these equations for when there is no GSIS and compare these with the widely accepted uniaxial strain storage coefficient associated with fluid movement in aquifers (e.g., Gambolati et al. 2000; Jaeger et al. 2007; Zimmerman 2017; Andersen et al. 2017).

The outline of the article is as follows. A modified form of Hooke's law is presented, which incorporates pore pressure and GSIS. It is then shown how to relate GSIS to the mass of adsorbed gas within the coal. A mass conservation equation is derived for gas migration in coal, which leads to a general expression for the aforementioned storage coefficient in terms of fluid compressibility, porosity, bulk strain, and GSIS. A general equation is developed to describe the associated change in porosity. Expressions for stress and bulk strain are derived assuming uniaxial strain conditions. Finally, three storage coefficients are derived using the porosity models of Cui and Bustin (2005), Palmer and Mansoori (1998), and Shi and Durucan (2004). Implications of the results are then discussed in the context of permeability modeling.

\section{Mathematical Model}

\subsection{Incorporation of Adsorption into Hooke's law}

In the context of coal-bed methane production, the following modified form of Hooke's law is generally adopted (consider Jaeger et al. 2007, p. 179)

$$
\mathrm{d} \boldsymbol{\varepsilon}=\frac{1}{2 G} \mathrm{~d} \boldsymbol{\tau}-\left[\frac{v}{2 G(1+v)} \operatorname{trace}(\mathrm{d} \boldsymbol{\tau})+\frac{\alpha \mathrm{d} P_{\mathrm{p}}}{3 K}-\frac{\mathrm{d} \varepsilon_{\mathrm{s}}}{3}\right] \mathbf{I}
$$

and

$$
\mathrm{d} \boldsymbol{\tau}=2 G \mathrm{~d} \boldsymbol{\varepsilon}+\left[\lambda \operatorname{trace}(\mathrm{d} \boldsymbol{\varepsilon})+\alpha \mathrm{d} P_{\mathrm{p}}-K \mathrm{~d} \varepsilon_{\mathrm{s}}\right] \mathbf{I}
$$

where $\boldsymbol{\varepsilon}(-)$ is the strain tensor, $\boldsymbol{\tau}\left(\mathrm{ML}^{-1} \mathrm{~T}^{-2}\right)$ is the stress tensor, $G\left(\mathrm{ML}^{-1} \mathrm{~T}^{-2}\right)$ is the shear modulus, $v(-)$ is Poisson's ratio, $\lambda\left(\mathrm{ML}^{-1} \mathrm{~T}^{-2}\right)$ is the Lamé parameter, $K\left(\mathrm{ML}^{-1} \mathrm{~T}^{-2}\right)$ is the bulk modulus, $\alpha(-)$ is the Biot coefficient, $P_{\mathrm{p}}\left(\mathrm{ML}^{-1} \mathrm{~T}^{-2}\right)$ is the pore pressure, and $\varepsilon_{\mathrm{S}}(-)$ is 
a shrinkage strain associated with methane adsorption, typically described using a Langmuir isotherm of the form (e.g., Ye et al. 2014)

$$
\varepsilon_{\mathrm{s}}=\frac{\varepsilon_{\mathrm{L}} P_{\mathrm{m}}}{P_{\mathrm{m}}+P_{\mathrm{L}}}
$$

where $P_{\mathrm{m}}\left(\mathrm{ML}^{-1} \mathrm{~T}^{-2}\right)$ is the partial pressure of the adsorbed methane and $\varepsilon_{\mathrm{L}}(-)$ and $P_{\mathrm{L}}$ $\left(\mathrm{ML}^{-1} \mathrm{~T}^{-2}\right)$ are empirical parameters.

The value of $\varepsilon_{\mathrm{L}}$ is negative in this context because $\varepsilon$ is a positive compression strain. The absolute value of $\varepsilon_{\mathrm{L}}$ represents the maximum possible volumetric expansion strain that can be incurred due to gas adsorption. The $P_{\mathrm{L}}$ parameter represents the value of $P_{\mathrm{m}}$ at which $\varepsilon_{\mathrm{S}}=\varepsilon_{\mathrm{L}} / 2$.

\subsection{Linking Adsorption Mass to Adsorption Strain}

The shrinkage due to gas sorption is thought to be mathematically analogous to volumetric strain associated with temperature change. An important point to note in this context is that (Grimvall 1999, p. 296)

$$
\frac{\partial \varepsilon_{\mathrm{m}}}{\partial T}=\frac{\partial \varepsilon_{\mathrm{b}}}{\partial T}
$$

where $T(\Theta)$ is temperature and $\varepsilon_{\mathrm{m}}(-)$ and $\varepsilon_{\mathrm{b}}(-)$ are mineral volume and bulk volume strains, respectively, found from

$$
\mathrm{d} \varepsilon_{\mathrm{m}}=-\frac{\mathrm{d} V_{\mathrm{m}}}{V_{\mathrm{m}}}
$$

and

$$
\mathrm{d} \varepsilon_{\mathrm{b}}=-\frac{\mathrm{d} V_{\mathrm{b}}}{V_{\mathrm{b}}}
$$

where $V_{\mathrm{m}}\left(\mathrm{L}^{3}\right)$ is volume of coal mineral contained within a given bulk volume, $V_{\mathrm{b}}\left(\mathrm{L}^{3}\right)$. Also note that

$$
V_{\mathrm{b}}=V_{\mathrm{m}}+V_{\mathrm{p}}
$$

where $V_{\mathrm{p}}\left(\mathrm{L}^{3}\right)$ is the pore volume.

Given the mathematical analogy between gas sorption and temperature, and noting that $\varepsilon_{\mathrm{b}}=\operatorname{trace}(\varepsilon)$, Eqs. (1), (3), and (4) suggest that

$$
\frac{\partial \varepsilon_{\mathrm{m}}}{\partial P_{\mathrm{m}}}=\frac{\partial \varepsilon_{\mathrm{b}}}{\partial P_{\mathrm{m}}}=\frac{\partial \varepsilon_{\mathrm{s}}}{\partial P_{\mathrm{m}}}=\frac{\varepsilon_{\mathrm{s}}^{2} P_{\mathrm{L}}}{\varepsilon_{\mathrm{L}} P_{\mathrm{m}}^{2}}
$$

An incremental increase in the mass of adsorbed methane, $\delta M_{s}(\mathrm{M})$, will result in an incremental increase in the coal-mineral volume of $\delta V_{\mathrm{m}}=\delta M_{s} / \rho_{\mathrm{S}}\left(\mathrm{L}^{3}\right)$ where $\rho_{\mathrm{S}}\left(\mathrm{ML}^{-3}\right)$ is the density of the adsorbed methane, which is assumed to be constant. It follows that the associated incremental increase in mineral strain $\delta \varepsilon_{\mathrm{m}}=-\delta M_{s} /\left(\rho_{\mathrm{s}} V_{\mathrm{m}}\right)$. Equation (8) therefore suggests that

$$
\frac{d M_{s}}{\rho_{\mathrm{s}} V_{\mathrm{b}}}=-(1-\phi) \mathrm{d} \varepsilon_{\mathrm{s}}
$$

where $\phi=V_{\mathrm{p}} / V_{\mathrm{b}}(-)$ is the porosity. 


\subsection{Mass Conservation Statement}

Following similar ideas to those presented by Jaeger et al. (2007, p. 184), a mass conservation statement for methane within a deformable mass of coal can take the form

$$
\frac{\partial \zeta}{\partial t}+\frac{1}{\rho_{\mathrm{g}}} \nabla \cdot\left(\rho_{\mathrm{g}} q\right)=0
$$

where $t(\mathrm{~T})$ is time and (consider Jaeger et al. 2007, p. 180)

$$
\mathrm{d} \zeta=\frac{\mathrm{d} M_{\mathrm{g}}+\mathrm{d} M_{s}}{\rho_{\mathrm{g}} V_{\mathrm{b}}}
$$

and

$$
\mathbf{q}=-\frac{\mathbf{k}}{\mu_{\mathrm{g}}} \nabla\left(P_{\mathrm{p}}+\rho_{\mathrm{g}} g z\right)
$$

where $M_{\mathrm{g}}(\mathrm{M})$ is the mass of gaseous methane contained within the bulk volume of coal, $V_{\mathrm{b}}$ $\left(\mathrm{L}^{3}\right), \rho_{\mathrm{g}}\left(\mathrm{ML}^{-3}\right)$ is the density of gaseous methane, $\mathbf{k}\left(\mathrm{L}^{2}\right)$ is permeability, $\mu_{\mathrm{g}}\left(\mathrm{ML}^{-1} \mathrm{~T}^{-1}\right)$ is the dynamic viscosity of gaseous methane, $g\left(\mathrm{LT}^{-2}\right)$ is gravitational acceleration, and $z(\mathrm{~L})$ is elevation.

In the context of coal-bed methane, the permeability is generally taken to be a scalar quantity found from (Palmer and Mansoori 1998; Seidle et al. 1992; Shi and Durucan 2004; Cui and Bustin 2005)

$$
k=k_{0}\left(\phi / \phi_{0}\right)^{\eta}
$$

where $k_{0}$ is the value of $k$ when $\phi=\phi_{0}, \phi_{0}$ is a reference value of the porosity and $\eta(-)$ is an empirical exponent (Pyrak-Nolte et al. 1998), generally assumed to be three (due to an association with the so-called match stick model, Seidle et al. 1992).

Let $m_{\mathrm{g}}=M_{\mathrm{g}} / V_{b}\left(\mathrm{ML}^{-3}\right)$ be the mass of gaseous methane per unit bulk volume of coal. It follows that

$$
\mathrm{d} \zeta=\frac{\mathrm{d} m_{\mathrm{g}}}{\rho_{\mathrm{g}}}-\frac{m_{\mathrm{g}} \mathrm{d} \varepsilon_{\mathrm{b}}}{\rho_{\mathrm{g}}}+\frac{\mathrm{d} M_{s}}{\rho_{\mathrm{g}} V_{\mathrm{b}}}
$$

Given Eq. (9) and also that $m_{\mathrm{g}}=\phi \rho_{\mathrm{g}}$, it can be further stated that

$$
\mathrm{d} \zeta=\phi C_{\mathrm{g}} \mathrm{d} P_{\mathrm{p}}+\mathrm{d} \phi-\phi \mathrm{d} \varepsilon_{\mathrm{b}}-(1-\phi) \frac{\rho_{\mathrm{s}}}{\rho_{\mathrm{g}}} \mathrm{d} \varepsilon_{\mathrm{s}}
$$

where $C_{\mathrm{g}}=\rho_{\mathrm{g}}^{-1} \partial \rho_{\mathrm{g}} / \partial P_{\mathrm{p}}\left(\mathrm{M}^{-1} \mathrm{LT}^{2}\right)$ is the compressibility of the gaseous methane.

The storage coefficient, $S\left(\mathrm{M}^{-1} \mathrm{LT}^{2}\right)$, is found from (Green and Wang 1990)

$$
S \equiv \frac{\partial \zeta}{\partial P_{\mathrm{p}}}=\phi C_{\mathrm{g}}+\frac{\partial \phi}{\partial P_{\mathrm{p}}}-\phi \frac{\partial \varepsilon_{\mathrm{b}}}{\partial P_{\mathrm{p}}}-(1-\phi) \frac{\rho_{\mathrm{s}}}{\rho_{\mathrm{g}}} \frac{\partial \varepsilon_{\mathrm{s}}}{\partial P_{\mathrm{p}}}
$$

\subsection{Determining the Change in Porosity}

Given that $\phi=V_{\mathrm{p}} / V_{\mathrm{b}}$ where $V_{\mathrm{p}}$ and $V_{\mathrm{b}}$ are both functions of $P_{\mathrm{p}}, P_{\mathrm{m}}$ and the mean stress, $\tau_{\mathrm{m}}=\operatorname{trace}(\boldsymbol{\tau}) / 3$, the change in porosity can be found from

$$
\frac{\mathrm{d} \phi}{\phi}=\left(C_{p p}-C_{b p}\right) \mathrm{d} P_{\mathrm{p}}+\left(C_{b c}-C_{p c}\right) \mathrm{d} \tau_{\mathrm{m}}+\left(\frac{\partial \varepsilon_{\mathrm{b}}}{\partial P_{\mathrm{m}}}-\frac{\partial \varepsilon_{\mathrm{p}}}{\partial P_{\mathrm{m}}}\right) \mathrm{d} P_{\mathrm{m}}
$$

where

$$
\mathrm{d} \varepsilon_{\mathrm{p}}=-\frac{\mathrm{d} V_{\mathrm{p}}}{V_{\mathrm{p}}}
$$


and

$$
\begin{gathered}
C_{b c}=\frac{\partial \varepsilon_{\mathrm{b}}}{\partial \tau_{\mathrm{m}}}, C_{b p}=-\frac{\partial \varepsilon_{\mathrm{b}}}{\partial P_{\mathrm{p}}} \\
C_{p c}=\frac{\partial \varepsilon_{\mathrm{p}}}{\partial \tau_{\mathrm{m}}}, C_{p p}=-\frac{\partial \varepsilon_{\mathrm{p}}}{\partial P_{\mathrm{p}}} .
\end{gathered}
$$

A result from Eq. (8) is that

$$
\frac{\partial \varepsilon_{\mathrm{b}}}{\partial P_{\mathrm{m}}}=\frac{\partial \varepsilon_{\mathrm{p}}}{\partial P_{\mathrm{m}}}
$$

Furthermore (Jaeger et al. 2007, p. 173),

$$
\begin{aligned}
& \phi\left(C_{p p}-C_{b p}\right)=\frac{\alpha-\phi}{K} \\
& \phi\left(C_{b c}-C_{p c}\right)=\frac{\phi-\alpha}{K}
\end{aligned}
$$

from which it follows that

$$
\mathrm{d} \phi=\frac{(\alpha-\phi)\left(\mathrm{d} P_{\mathrm{p}}-\mathrm{d} \tau_{\mathrm{m}}\right)}{K}
$$

\subsection{Imposing Uniaxial Strain Conditions}

Following Palmer and Mansoori (1998), Shi and Durucan (2004), and Cui and Bustin (2005), uniaxial strain conditions are assumed whereby $\varepsilon_{x x}=\varepsilon_{y y}=0$ and $\varepsilon_{\mathrm{b}}=\varepsilon_{z z}$. Equation (2) reveals that under such conditions

$$
\mathrm{d} \varepsilon_{\mathrm{b}}=\frac{\mathrm{d} \tau_{z z}-\alpha \mathrm{d} P_{\mathrm{p}}+K \mathrm{~d} \varepsilon_{\mathrm{s}}}{2 G+\lambda}
$$

and, furthermore, that

$$
\mathrm{d} \tau_{x x}=\mathrm{d} \tau_{y y}=\frac{\lambda \mathrm{d} \tau_{z z}}{2 G+\lambda}+\frac{2 G\left(\alpha \mathrm{d} P_{\mathrm{p}}-K \mathrm{~d} \varepsilon_{\mathrm{s}}\right)}{2 G+\lambda}
$$

and (note that $3 \lambda=3 K-2 G$ )

$$
\mathrm{d} \tau_{\mathrm{m}}=\frac{3 K \mathrm{~d} \tau_{z z}+4 G\left(\alpha \mathrm{d} P_{\mathrm{p}}-K \mathrm{~d} \varepsilon_{\mathrm{s}}\right)}{3(2 G+\lambda)}
$$

In the absence of gas adsorption (i.e., $\varepsilon_{L}=0$ and/or $\partial \varepsilon_{\mathrm{s}} / \partial P_{\mathrm{p}}=0$ ), uniaxial strain conditions (as described above) allow Eq. (16) to reduce to (Gambolati et al. 2000; Jaeger et al. 2007; Zimmerman 2017; Andersen et al. 2017)

$$
\lim _{\varepsilon_{\mathrm{L}} \rightarrow 0} S=\phi C_{\mathrm{g}}+\frac{(1-\alpha)(\alpha-\phi)}{K}+\frac{\alpha^{2}}{2 G+\lambda}
$$

Note that the $\tau_{z z}$ term is not present in Eq. (27) because it is also assumed that $\tau_{z z}$ is only dependent on the weight of the overburden and therefore independent of $P_{\mathrm{p}}$.

\subsection{Application of the Cui and Bustin Model}

The assumptions listed above are consistent with those originally adopted by Cui and Bustin (2005). Indeed, substituting Eq. (26) into Eq. (23) leads to (Cui and Bustin 2005)

$$
\mathrm{d} \phi=(\alpha-\phi)\left[\left(\frac{1-\alpha}{K}+\frac{\alpha}{2 G+\lambda}\right) \mathrm{d} P_{\mathrm{p}}-\frac{\mathrm{d} \tau_{z z}}{2 G+\lambda}+\frac{4 G \mathrm{~d} \varepsilon_{\mathrm{s}}}{3(2 G+\lambda)}\right]
$$


Substituting Eqs. (24) and (28) into Eq. (15) then leads to

$$
\begin{aligned}
\mathrm{d} \zeta= & {\left[\phi C_{\mathrm{g}}+\frac{(1-\alpha)(\alpha-\phi)}{K}+\frac{\alpha^{2}}{2 G+\lambda}\right] \mathrm{d} P_{\mathrm{p}}-\frac{\alpha \mathrm{d} \tau_{z z}}{2 G+\lambda} } \\
& -\left[\frac{[3 K+4(1-\alpha) G]}{3(2 G+\lambda)}-\frac{\left(\rho_{\mathrm{g}}-\rho_{\mathrm{s}}\right)(1-\phi)}{\rho_{\mathrm{g}}}\right] \mathrm{d} \varepsilon_{\mathrm{s}}
\end{aligned}
$$

such that Eq. (16) reveals that

$$
S=\phi C_{\mathrm{g}}+\frac{(1-\alpha)(\alpha-\phi)}{K}+\frac{\alpha^{2}}{2 G+\lambda}-\left[\frac{[3 K+4(1-\alpha) G]}{3(2 G+\lambda)}-\frac{\left(\rho_{\mathrm{g}}-\rho_{\mathrm{s}}\right)(1-\phi)}{\rho_{\mathrm{g}}}\right] \frac{\partial \varepsilon_{\mathrm{s}}}{\partial P_{\mathrm{p}}}
$$

Note that Eq. (30) exactly reduces to Eq. (27) when $\varepsilon_{\mathrm{L}}=0$.

\subsection{Application of the Palmer and Mansoori Model}

Palmer and Mansoori (1998) apply an alternative porosity equation, originally proposed in an unpublished correspondence from Nigel Higgs, which reads as follows

$$
\begin{aligned}
-\mathrm{d} \phi= & {\left[\frac{1}{2 G+\lambda}-(1-\phi)(1-\alpha) \frac{f}{K}\right]\left(\mathrm{d} \tau_{z z}-\mathrm{d} P_{\mathrm{p}}\right) } \\
& +\left[\frac{1}{2 G+\lambda}-\frac{(1-\phi)}{K}\right]\left((1-\alpha) \mathrm{d} P_{\mathrm{p}}+K \mathrm{~d} \varepsilon_{\mathrm{s}}\right)
\end{aligned}
$$

where $f(-)$ is described as a "fraction" that ranges from zero to one. Based on a discussion by Moor et al. (2015), Zimmerman (2017) suggested that $f$ is thought to relate to the ratio of isotropic strain to deviatoric strain within the mineral grains of the rock of concern. Note that Palmer and Mansoori (1998) state that Eq. (31) can be derived by assuming uniaxial strain conditions, as described above.

Eq. (31) can be rearranged to get

$$
\begin{aligned}
\mathrm{d} \phi= & {\left[\frac{(1-\alpha)(1-\phi)(1-f)}{K}+\frac{\alpha}{2 G+\lambda}\right] \mathrm{d} P_{\mathrm{p}} } \\
& -\left[\frac{1}{2 G+\lambda}-(1-\alpha)(1-\phi) \frac{f}{K}\right] \mathrm{d} \tau_{z z}-\left[\frac{K}{2 G+\lambda}-(1-\phi)\right] \mathrm{d} \varepsilon_{\mathrm{s}}
\end{aligned}
$$

Substituting Eqs. (24) and (32) into Eq. (15) then leads to

$$
\begin{aligned}
\mathrm{d} \zeta= & {\left[\phi C_{\mathrm{g}}+\frac{(1-\alpha)(1-\phi)(1-f)}{K}+\frac{\alpha(1+\phi)}{2 G+\lambda}\right] \mathrm{d} P_{\mathrm{p}} } \\
& -\left[\frac{1+\phi}{2 G+\lambda}-(1-\alpha)(1-\phi) \frac{f}{K}\right] \mathrm{d} \tau_{z z}-\left[\frac{K(1+\phi)}{2 G+\lambda}-\frac{\left(\rho_{\mathrm{g}}-\rho_{\mathrm{s}}\right)(1-\phi)}{\rho_{\mathrm{g}}}\right] \mathrm{d} \varepsilon_{\mathrm{s}}
\end{aligned}
$$

such that Eq. (16) leads to

$$
\begin{aligned}
S= & \phi C_{\mathrm{g}}+\frac{(1-\alpha)(1-\phi)(1-f)}{K}+\frac{\alpha(1+\phi)}{2 G+\lambda} \\
& -\left[\frac{K(1+\phi)}{2 G+\lambda}-\frac{\left(\rho_{\mathrm{g}}-\rho_{\mathrm{s}}\right)(1-\phi)}{\rho_{\mathrm{g}}}\right] \frac{\partial \varepsilon_{\mathrm{s}}}{\partial P_{\mathrm{p}}}
\end{aligned}
$$


As previously shown by Zimmerman (2017), regardless of the choice of value of $f$, Eqs. (33) and (34) only reduce to Eqs. (29) and (30) when $\phi=0$ and $\alpha=1$. It follows that Eq. (31) is invalid when $\phi>0$ or $\alpha<1$.

\subsection{Application of the Shi and Durucan Model}

Under hydrostatic stress conditions, $\mathrm{d} \boldsymbol{\tau}=\mathrm{d} P_{\mathrm{p}} \mathbf{I} \equiv \mathrm{d} \tau_{\mathrm{h}} \mathbf{I}$ (Jaeger et al. 2007, p. 182) where $\tau_{\mathrm{h}}\left(\mathrm{ML}^{-1} \mathrm{~T}^{-2}\right)$ is the hydrostatic stress. In this context, Seidle et al. (1992) suggest that the change in porosity can be described by a pore compressibility parameter, $C_{\mathrm{p}}\left(\mathrm{M}^{-1} \mathrm{LT}^{2}\right)$, defined by

$$
C_{\mathrm{p}}=-\frac{1}{\phi} \frac{\partial \phi}{\partial \tau_{\mathrm{h}}}
$$

Shi and Durucan (2004) further suggest that such an equation should also hold under uniaxial strain conditions and state that

$$
\mathrm{d} \phi=-\phi C_{\mathrm{p}}\left(\mathrm{d} \tau_{x x}-\alpha \mathrm{d} P_{\mathrm{p}}\right)
$$

Substituting Eq. (25) into Eq. (36) then leads to

$$
\mathrm{d} \phi=-\frac{\phi C_{\mathrm{p}}\left[\lambda\left(\mathrm{d} \tau_{z z}-\alpha \mathrm{d} P_{\mathrm{p}}\right)-2 G K \mathrm{~d} \varepsilon_{\mathrm{s}}\right]}{2 G+\lambda}
$$

and substituting Eqs. (24) and (37) into Eq. (15) gives us

$$
\begin{aligned}
\mathrm{d} \zeta= & {\left[\phi C_{\mathrm{g}}+\frac{\phi \alpha\left(C_{\mathrm{p}} \lambda+1\right)}{2 G+\lambda}\right] \mathrm{d} P_{\mathrm{p}}-\frac{\phi\left(C_{\mathrm{p}} \lambda+1\right) \mathrm{d} \tau_{z z}}{2 G+\lambda} } \\
& -\left[\frac{\phi K\left(1-2 C_{p} G\right)}{2 G+\lambda}+\frac{\rho_{\mathrm{s}}}{\rho_{\mathrm{g}}}(1-\phi)\right] \mathrm{d} \varepsilon_{\mathrm{s}}
\end{aligned}
$$

such that Eq. (16) leads to

$$
S=\phi C_{\mathrm{g}}+\frac{\phi \alpha\left(C_{\mathrm{p}} \lambda+1\right)}{2 G+\lambda}-\left[\frac{\phi K\left(1-2 C_{p} G\right)}{2 G+\lambda}+\frac{\rho_{\mathrm{s}}}{\rho_{\mathrm{g}}}(1-\phi)\right] \frac{\partial \varepsilon_{\mathrm{s}}}{\partial P_{\mathrm{p}}}
$$

Shi and Durucan (2004) suggest that $C_{\mathrm{p}}$ should be obtained by calibration to experimental data. However, a theoretical expression for $C_{\mathrm{p}}$ can be obtained by matching the $\partial \varepsilon_{\mathrm{s}} / \partial P_{\mathrm{p}}$ terms in both Eqs. (30) and (39), which leads to

$$
C_{\mathrm{p}}=\frac{2(\alpha-\phi)}{3 \phi K}=\frac{2\left(C_{p p}-C_{b p}\right)}{3}
$$

Unfortunately, substituting Eq. (40) back into Eq. (39) and then setting $\partial \varepsilon_{\mathrm{s}} / \partial P_{\mathrm{p}}=0$ do not lead to the storage coefficient expression given in Eq. (27). The reason is that there are inconsistencies in the theoretical derivations of both Seidle et al. (1992) and Shi and Durucan (2004). The first problem is that Shi and Durucan (2004) derive an expression for $\tau_{x x}$ based on uniaxial strain conditions and then apply this to an equation that has been derived assuming hydrostatic stress conditions. The next problem is that under hydrostatic conditions, $d \tau_{\mathrm{m}}=\mathrm{d} P_{\mathrm{p}}$. It follows from Eq. (23) that $\mathrm{d} \phi=0$. Therefore, Eq. (35) is not theoretically valid under hydrostatic conditions. Instead, Eq. (35) should be thought of as a heuristic function with an unspecified theoretical basis. 


\section{Implications for Permeability Modeling}

Partially differentiating Eq. (28) with respect to $P_{\mathrm{p}}$ leads to

$$
\frac{1}{\phi} \frac{\partial \phi}{\partial P_{p}}=\left(C_{p p}-C_{b p}\right)\left[\left(1-\alpha+\frac{\alpha(1+v)}{3(1-v)}\right)+\frac{2 E}{9(1-v)} \frac{\partial \varepsilon_{\mathrm{s}}}{\partial P_{\mathrm{p}}}\right]
$$

where $\left(C_{p p}-C_{b p}\right)$ is defined in Eq. (21) and $E\left(\mathrm{ML}^{-1} \mathrm{~T}^{-2}\right)$ and $v(-)$ are the Young's modulus and Poisson's ratio, respectively.

It is further assumed that $P_{\mathrm{m}}=P_{\mathrm{p}}$ and $\left(C_{p p}-C_{b p}\right)$ is constant. Integrating Eq. (41) with respect to $P_{\mathrm{p}}$ and substituting the result into Eq. (13) then lead to (Cui and Bustin 2005)

$$
\frac{k}{k_{0}}=\exp \left[A\left(P_{\mathrm{p}}-P_{\mathrm{p} 0}\right)+B\left(\frac{P_{\mathrm{p}}}{P_{\mathrm{p}}+P_{\mathrm{L}}}-\frac{P_{\mathrm{p} 0}}{P_{\mathrm{p} 0}+P_{\mathrm{L}}}\right)\right]
$$

where

$$
A=\eta\left(C_{p p}-C_{b p}\right)\left(1-\alpha+\frac{\alpha(1+v)}{3(1-v)}\right) \quad \text { and } \quad B=\frac{2 \eta\left(C_{p p}-C_{b p}\right) E \varepsilon_{\mathrm{L}}}{9(1-v)}
$$

and $P_{\mathrm{p} 0}\left(\mathrm{ML}^{-1} \mathrm{~T}^{-2}\right)$ is the reference pore pressure at which $k=k_{0}$.

Applying the same set of procedures to Eq. (37) also leads to Eq. (42) but with (Shi and Durucan 2004)

$$
A=\frac{\eta C_{\mathrm{p}} \alpha \nu}{1-v} \quad \text { and } \quad B=\frac{\eta C_{\mathrm{p}} E \varepsilon_{\mathrm{L}}}{3(1-v)}
$$

The analysis in this article has shown that Eq. (42) in conjunction with Eq. (43), due to Cui and Bustin (2005), is consistent with conventional poroelastic theory and uniaxial strain conditions. In contrast, Eq. (44), due to Shi and Durucan (2004), is theoretically inconsistent. However, in the literature it is found that Eq. (44) is better able to capture the response of experimentally observed permeability data, as compared to Eq. (43) (e.g., Shi et al. 2014; Zeng and Wang 2017). The reason for this is that $\eta$ is generally restricted to three (to reflect the match stick model). Consequently, Eq. (43) only has one fitting parameter for this purpose, namely $\varepsilon_{\mathrm{L}}$. In contrast, Eq. (44) has two fitting parameters $C_{\mathrm{p}}$ and $\varepsilon_{\mathrm{L}}$, and therefore will inevitably be easier to fit to observed data. In practice, the value of $\eta$ is often unpredictable (Pyrak-Nolte et al. 1998). If $\eta$ is treated as an additional fitting parameter, Eq. (43) will have the same degrees of freedom as Eq. (44) and the Cui and Bustin (2005) permeability model will be able to fit experimental data in exactly the same way as the Shi and Durucan (2004) model but with the important added advantage that a theoretically consistent storage coefficient can also be derived.

\section{Conclusions}

Theoretical equations have been derived to describe porosity change and storage coefficient in coal-bed methane systems under both general and uniaxial strain conditions. Three equations for the storage coefficient were then derived using the porosity models of Cui and Bustin (2005), Palmer and Mansoori (1998), and Shi and Durucan (2004). For the limiting case when there is no gas adsorption, only the storage coefficient derived using the Cui and Bustin (2005) porosity model correctly reduced to an established expression for the storage coefficient in an aquifer under uniaxial strain conditions. The storage coefficient derived using the Palmer and Mansoori (1998) porosity model was found to provide the correct limiting result only 
when the Biot coefficient is assumed to be one and the porosity is assumed to be zero. The storage coefficient derived using the Shi and Durucan (2004) porosity model is found not to have the correct limit because its derivation involves a mixture of hydrostatic and uniaxial stress assumptions. Out of the three models, only the Cui and Bustin (2005) porosity model is shown to rigourously satisfy poroelastic theory under uniaxial strain conditions.

Open Access This article is distributed under the terms of the Creative Commons Attribution 4.0 International License (http://creativecommons.org/licenses/by/4.0/), which permits unrestricted use, distribution, and reproduction in any medium, provided you give appropriate credit to the original author(s) and the source, provide a link to the Creative Commons license, and indicate if changes were made.

\section{References}

Andersen, O., Nilsen, H.M., Gasda, S.: Modeling geomechanical impact of fluid storage in poroelastic media using precomputed response functions. Comput. Geosci. 21, 1135-1156 (2017)

Cui, X., Bustin, R.M.: Volumetric strain associated with methane desorption and its impact on coalbed gas production from deep coal seams. AAPG Bull. 89, 1181-1202 (2005)

Gambolati, G., Bau, D., Teatini, P., Ferronato, M.: Importance of poroelastic coupling in dynamically active aquifers of the Po river basin, Italy. Water Resour. Res. 36, 2443-2459 (2000)

Green, D.H., Wang, H.F.: Specific storage as a poroelastic coefficient. Water Resour. Res. 26(7), 1631-1637 (1990)

Grimvall, G.: Thermophysical Properties Materials. Elsevier, North-Holland (1999)

Gu, F., Chalaturnyk, R.J.: Numerical simulation of stress and strain due to gas sorption/desorption and their effects on in situ permeability of coalbeds. J. Can. Pet. Technol. 45, 52-62 (2006)

Jaeger, J.C., Cook, N.G.W., Zimmerman, R.W.: Fundamentals of Rock Mechanics, 4th edn. Wiley, Hoboken (2007)

Li, C., Wang, Z., Shi, L., Feng, R.: Analysis of analytical models developed under the uniaxial strain condition for predicting coal permeability during primary depletion. Energies 10(11), 1849 (2017)

Liu, S., Harpalani, S.: Permeability prediction of coalbed methane reservoirs during primary depletion. Int. J. Coal Geol. 113, 1-10 (2013)

Moore, R., Palmer, I., Higgs, N.: Anisotropic model for permeability change in coalbed-methane wells. SPE Reserv. Eval. Eng. 18(04), 456-462 (2015)

Palmer, I.: Permeability changes in coal: analytical modeling. Int. J. Coal Geol. 77, 119-126 (2009)

Palmer, I., Mansoori, J.: How permeability depends on stress and pore pressure in coalbeds: a new model. SPE Reserv. Eval. Eng. 1, 539-544 (1998)

Pyrak Nolte, L.J., Cook, N.G., Nolte, D.D.: Fluid percolation through single fractures. Geophys. Res. Lett. 15(11), 1247-1250 (1988)

Seidle, J.P., Jeansonne, M.W., Erickson, D.J.: Application of matchstick geometry to stress dependent permeability in coals. In: SPE Rocky Mountain Regional Meeting. Society of Petroleum Engineers, SPE 24361 (1992)

Shi, J.Q., Durucan, S.: Drawdown induced changes in permeability of coalbeds: a new interpretation of the reservoir response to primary recovery. Transp. Porous Media 56, 1-16 (2004)

Shi, J.Q., Pan, Z., Durucan, S.: Analytical models for coal permeability changes during coalbed methane recovery: model comparison and performance evaluation. Int. J. Coal Geol. 136, 17-24 (2014)

Wu, G., Jia, S., Wu, B., Yang, D.: A discussion on analytical and numerical modelling of the land subsidence induced by coal seam gas extraction. Environ. Earth Sci. 77(9), 353 (2018)

Ye, Z., Chen, D., Wang, J.G.: Evaluation of the non-Darcy effect in coalbed methane production. Fuel 121, $1-10(2014)$

Zeng, Q., Wang, Z.: A new cleat volume compressibility determination method and corresponding modification to coal permeability model. Transp. Porous Media 119(3), 689-706 (2017)

Zimmerman, R.W.: Pore volume and porosity changes under uniaxial strain conditions. Transp. Porous Media 119(2), 481-498 (2017)

Publisher's Note Springer Nature remains neutral with regard to jurisdictional claims in published maps and institutional affiliations. 